\title{
The Arachnology Collection at the Denver Museum of Nature \& Science
}

Jeffrey T. Stephenson ₹

$\ddagger$ Denver Museum of Nature \& Science, Denver, CO, United States of America

Corresponding author: Jeffrey T. Stephenson (jeff.stephenson@dmns.org)

Received: 13 Apr 2018| Published: 13 Jun 2018

Citation: Stephenson J (2018) The Arachnology Collection at the Denver Museum of Nature \& Science.

Biodiversity Information Science and Standards 2: e25810. https://doi.org/10.3897/biss.2.25810

\begin{abstract}
The Arachnology collection at the Denver Museum of Nature \& Science (DMNS) was founded 20 years ago. We describe its inception and early growth from 0 to over 62,000 lots; DMNS volunteers and the key role they play as citizen scientists in the Colorado Spider Survey and collections work such as identification and databasing. We now have more than 40,000 databased and geocoded specimen vials available through Symbiota and GBIF. The collection's research focuses on the biodiversity of the region's spiders, scorpions, cave forms, and solifuge (camel spiders). DMNS is now one of the centers for research on solifuge.
\end{abstract}

\section{Keywords}

Colorado spider survey, biodiversity, collections development, solifuge

\section{Presenting author}

Jeffrey T. Stephenson 


\section{Author contributions}

Paula E. Cushing, Ph.D. 